\title{
Selected anthropometric indices of maritime university students
}

\section{Ewa Rębacz-Maron}

\author{
Department of Vertebrate Zoology and Anthropology, University of Szczecin, Szczecin, Poland
}

\begin{abstract}
Background: Overweight and obesity during working life are becoming an increasingly serious challenge to various professional groups where recruits and personnel must be healthy and fit. Marine recruitment, even at the training stage, should be open to applicants who meet health and fitness criteria. The objective of the study is to determine the overweight and adiposity rates among seafarer candidates $(n=368)$. Based on anthropometric measurements and somatic indices the extent of obesity among marine students/ /future seafarers was investigated.

Materials and methods: In the groups identified according to the year of study, arithmetic averages (SD - standard deviation) were calculated for somatometric characteristics, and were then used to analyse the phenomena of overweight and obesity. The comparison was performed using the Kruskal-Wallis test, one-way analysis of variance (ANOVA) by ranks.

Results: The highest average body mass index (BMI) score was found in fourth-year students (mean BMI $25.7 \pm 2.8$ ). The average BMI for years one and two was in the upper range of 'healthy' weight. In $24.0 \%$ of first-year students and $32.2 \%$ of second-year students, the waist circumference was higher than half of the body height. Body fat percentage results indicate that this feature is highly variable, with a strong upward trend.

Conclusions: Findings regarding overweight among future seamen give cause for concern. The participants of the study were characterised by excessive weight and adiposity. Recruitment criteria for uniformed services are not as restrictive as they used to be, as it is getting increasingly more difficult to find sufficiently slim and fit applicants.
\end{abstract}

(Int Marit Health 2015; 66, 3: 145-151)

\section{Key words: body build, seaman, body mass index (BMI), waist-to-hip ratio (WHR), waist-to-height ratio (WHtR), Rohrer's Index, waist circumference (WC), body impedance analysis (BIA)}

\section{INTRODUCTION}

World Health Organisation (WHO) is warning that more than 1 billion adults worldwide are overweight and 300 million of them are obese [1]. According to the organisation: "Obesity is one of today's most blatantly visible - yet most neglected - public health problems. Paradoxically coexisting with undernutrition, an escalating global epidemic of overweight and obesity - 'globesity' - is taking over many parts of the world" [2]. Data on obesity epidemic come mainly from highly developed countries, but increasing rates of obesity are also reported more and more often in countries with strong social stratification. Overweight and obesity are becoming a cosmopolitan phenomenon and a defining characteristic of the $21^{\text {st }}$ century. Increasingly, overweight is treated as a serious public concern which significantly affects the incidence of cardiovascular disease, hypertension, and type 2 diabetes [3]. On an individual scale, overweight and obesity can strongly undermine one's self-confidence and self-esteem. For societies, "excess kilograms" weigh down healthcare costs. It is believed that the periods of childhood, adolescence and young adulthood 
are critical in terms of the emergence of problems related to maintaining normal weight, especially due to chronic overfeeding $[4,5]$. Overweight and obesity bring a multitude of implications for adults, also affecting their professional lives. For the employer, the obese employee is a potential absentee on sick leave and their condition means that their workstation and job description must be adapted to the limitations imposed by their weight. The "globesity" phenomenon is no longer unheard of among people in occupations which used to demand health and fitness of recruits and practitioners. A trim figure was and still is necessary in nearly all jobs that require strength and endurance. Those who work at sea should still be selected from among the best, i.e. the fittest, healthiest and with the most stamina. Never in the human history has there been such a high percentage of overweight people in the population. This problem makes it difficult to select candidates for the "uniformed professions".

The onslaught of the obesity epidemic is accompanied by the development of new methods for assessing body adiposity, while the existing ones are revised. The most popular somatic indices include: body mass index (BMI), waist-to-hip ratio (WHR), waist-to-height ratio (WHtR), and Rohrer's Index. These indices are calculated from anthropometric measurements: body height (B-v), body weight, waist circumference (WC) and hip circumference. More and more often, adiposity is measured by means of the bioelectrical impedance analysis (BIA). In general use, the latter method is now replacing the traditional anthropometric measurements. It may be useful in assessing the body fat in healthy individuals, but it can also be of assistance in clinical trials and epidemiological studies. None of the methods for measuring body fat, however, can be regarded as free from disadvantages.

Despite its weaknesses, the most widely used somatic parameter in non-invasive body mass testing remains the BMI. BMI calculation is one of the best known and most universal parameters. For several decades, BMI was recommended by the $\mathrm{WHO}$ as the primary criterion for evaluating nutritional status and body weight [6]. Its popularity stems from the fact that it is technically uncomplicated, non-invasive, easy to measure and calculate. BMI, however, does not indicate the body build type or lean-to-fat ratio. The broad normal range of BMI [6] means that in epidemiological studies it is easy to make an error in categorisation, by categorising as normal people who are actually underweight or overweight, depending on body type. The BMI does not differentiate lean mass from fat mass, which can lead to the wrong interpretation of results in muscular individuals. The same BMI in two different people can correspond to different levels of muscularity or adiposity. For this reason, it is suggested that BMI should be accompanied by other measures as more useful for identifying (the degree of) adiposity: WHR, WHtR, WC, Rohrer's Index, and other [7-12].
Waist circumference is regarded as a somatic measure in and of itself. Based on B-v one can calculate the WC threshold that should not be exceeded. In line with the principle: "Keep your waist circumference to less than half your height". A study by Ashwell et al. [13] demonstrated that people whose WC was $\leq$ half their B-v enjoyed better health. The most dangerous, health-wise, location for excess fat to accumulate in the body is in one's abdomen. The fat accumulated there is metabolically active, and excess abdominal (visceral) fat can induce increased sugar levels in the blood, arterial hypertension, etc. It is possible to have a normal BMI score and at the same time excess amounts of fat stored within the abdomen (metabolically obese normal-weight).

The aim of this paper is to analyse the prevalence of overweight and type of body fat distribution among the students of the Maritime University of Szczecin, Poland. Somatic indices and BIA were used to investigate the prevalence of overweight and degree of adiposity among the candidates for careers at sea. The participants, having completed their course of study and professional training should be physically fit to apply for jobs as seamen.

\section{MATERIALS AND METHODS}

The research sample was made up of a group of young men, students of the Maritime University of Szczecin, Poland. The research underlying this study was conducted in April and May 2006 and 2007, and during the admissions procedure for the academic year 2006/2007. Anthropometric measurements and survey data were collected during physical education classes in the swimming pool with the consent of the university authorities. Students joined the study on a voluntary basis and refusal to join did not incur any consequences. Out of the initial examined group ( $n=368$ ), the researcher excluded individuals who did not complete the admissions process ( $n=12 ; 3.6 \%$ ) or changed schools ( $n=16 ; 4.4 \%$ ) within weeks of the beginning of the academic year. Those who qualified for further statistical analysis $(n=340)$ were divided according to the year of study - first year: $n=167$ (49.1\%); second year: $n=121(35.6 \%)$; third year: $n=18(5.3 \%)$; fourth year: $n=34$ (10.0\%).

Body measurements were performed with anthropometric equipment in compliance with the principles adopted in anthropometry [14]. In this paper, the following measurements were taken into account: B-v [cm], body weight [kg], WC [cm], hip circumference [cm]. Body height was measured with an anthropometer with an accuracy of $0.1 \mathrm{~cm}$; body circumferences were measured using a metric tape with an accuracy of $0.5 \mathrm{~cm}$; body weight was measured using SOEHNLE electronic scales (model 63671 Chicago Silver Body Balance Scale B000FL3H3G) with an accuracy of $100 \mathrm{~g}$. 
The use of weighing scales with bioimpedance technology made it possible to gather body composition data on the percentages of $\mathrm{H}_{2} \mathrm{O}$, fat and muscle mass in the body.

From the anthropometric measurements, somatic indices were calculated: BMI, WHR, WHtR and Rohrer's Index:

- $\mathrm{BMI}=$ body weight $[$ in $\mathrm{kg}] /(\mathrm{B}-\mathrm{v})[\text { in } \mathrm{m}]^{2}$. Results were interpreted based on the WHO classification, where BMI $\leq 18.49$ corresponds to underweight, BMI 18.50-24.99 normal (healthy weight) range, and $\mathrm{BMI} \geq 25.00$ overweight [6].

- WHR = waist circumference $[$ in $\mathrm{cm}] /$ hip circumference [in $\mathrm{cm}$ ]. Indicates visceral fat deposits in men when the score is $\geq 1.0$ [15], describes the type of fat distribution in the body.

- WHtR = waist circumference [in $\mathrm{cm}] /(\mathrm{B}-\mathrm{v})[$ in $\mathrm{cm}] . \mathrm{In}$ terpretation: WHtR $\geq 0.56$ is a predictor for developing type 2 diabetes, and WHtR $\geq 0.59$ predicts an increased risk of developing arterial hypertension [3]. The healthy range corresponds to the ratio less than 0.5 ; while the overweight ratio is $>0.5[16,17]$. WHtR seems to solve the problems inherent in the BMI and allows for a more accurate diagnosis and categorisation of the excess fat problem.

- Rohrer's Index = body weight $[\mathrm{g}] /(\mathrm{B}-\mathrm{v})^{3}[\mathrm{~cm}] \times 100$; interpretation for men: aged 19 years of age $\leq 1.29$ corresponds to the slender body type, $1.30 \geq$ stout body type; aged $20 \leq 1.31$ slender type, $1.32 \geq$ stout type; aged $21 \leq 1.33$ slender type, $1.34 \geq$ stout type; aged $22 \leq 1.34$ slender type, $1.35 \geq$ stout type; aged 23 $\leq 1.35$ slender type, $1.36 \geq$ stout type; aged $24 \leq 1.36$ slender type, $1.37 \geq$ stout type; aged $25 \leq 1.38$ slender type, $1.39 \geq$ stout type; aged $26-30 \leq 1.39$ slender type, $1.40 \geq$ stout type [15].

- $W C=$ waist circumference $[$ in $\mathrm{cm}]$-waist girth exceeding half of the body height, i.e. 1/2 (B-v) in a participant was interpreted as overweight $[18,19]$. The score was calculated using the formula: $1 / 2$ (B-v)-WC. Participants were classified according to the following criteria: $W C \leq 1 / 2(B-v)$ is normal body weight and $W C>1 / 2(B-v)$ is overweight.

- Body fat percentage is a measure of adiposity. There is no consensus as to the scope and strength of impact excess adiposity has on morbidity and mortality. It was assumed that for the participants with BMI scores $<18.5$, the body fat percentage amounted to $\leq 8 \%$; for individuals with $\mathrm{BMI}$ scores $>18.5$ and $\mathrm{BMI}$ $<25$, the body fat percentage should be in the range between $8 \%$ and $20 \%$; while for participants whose $\mathrm{BMI}$ scores were $>25$ and $\mathrm{BMI}<30$, the body fat percentage should range from $20 \%$ to $25 \%$. In individuals with $\mathrm{BMI}$ scores $>30$, the body fat percentage amounts to $>25 \%[20]$.
Once the groups were identified, body measurements and somatic indices were subject to analysis to calculate the arithmetic average $(\bar{X})$, standard deviation (SD), and range (min-max), while indices were compared to pre-determined categories (standards).

The collected survey data included information on the date of birth and year of study. To compare the arithmetic averages $(\mathrm{X})$ of the measurements, indices, and survey data according to the year of study, the author used the Kruskal-Wallis test, oneway ANOVA by ranks, the non-parametric equivalent of one-way analysis of variance. A non-parametric test was used due to the division into categories of somatic indices and a variable number of students in individual years of study. Moreover, some measurable variables did not meet the "normal distribution" criterion. If a test result was statistically significant, post-hoc tests (multiple comparisons) were performed.

The results were statistically analysed using the software package Statistica 10.0 PL made by StatSoft, Inc. (2011).

\section{RESULTS}

Table 1 lists the basic anthropometric measurements and somatic indices calculated. The highest average body height and body weight was found in third-year students (respectively: $\bar{X}=181.9 \pm 5.5 \mathrm{~cm} ; \bar{X}=85.2 \pm 12.2 \mathrm{~kg}$ ). The highest average $\mathrm{BMl}$ score was found in fourth-year students $\bar{X}=25.7 \pm 2.8$. A slightly lower average BMI score was found in third-year students $\bar{X}=25.3 \pm 2.9$. The mean BMl of the total group of third and fourth year students was above the normal range and could be classified as overweight. The average BMI scores for years one and two were in the upper range of "healthy" weight (respectively: $\bar{X}=23.6 \pm 3.2$ and $=24.3 \pm 3.1$ ). The Kruskal-Wallis test demonstrated that the BMI arithmetic averages for years three and four were statistically different from the averages for years one and two $(H=19.7, p<0.001)$ (Fig. 1). At the same time, in the first two years of study the BMI scores were found to fall in the broadest range (min-max) (Table 1).

The arithmetic averages of WHR for first-and second-year students did not exceed 1.0. Two individuals (1.2\%) among first-year students had WHR $\geq 1.0$ (Tables 1, 2).

According to Rohrer's Index averages, second-, third-, and fourth-year students had a stout body build. The "stout body build" type was represented by $47.3 \%$ of first-year students, $48.8 \%$ of second-year students and $66.7 \%$ and $61.8 \%$, respectively in the third and fourth year. The arithmetic average of Rohrer's Index for first-year students $(\bar{X}=1.3 \pm 0.2)$ was at the upper limit of the index for 20-year-olds. A comparison of Rohrer's Index averages using the Kruskal-Wallis ANOVA test demonstrated statistical significance for $\mathrm{H}=17.1 ; \mathrm{p}<0.001$ (Fig. 2). The post-hoc analysis showed that the average score for fourth-year students was statistically different way from the averages in the remaining years for $p=0.003$ (Table 1 ). 
Table 1. Description of the basic anthropometric measurements and somatic indices

\begin{tabular}{|c|c|c|c|c|c|c|c|c|}
\hline \multirow[t]{3}{*}{ Description } & \multicolumn{8}{|l|}{ Year of study } \\
\hline & \multicolumn{2}{|c|}{ First $(n=167)$} & \multicolumn{2}{|c|}{ Second $(n=121)$} & \multicolumn{2}{|c|}{ Third $(n=18)$} & \multicolumn{2}{|c|}{ Fourth $(n=34)$} \\
\hline & $\bar{X} \pm$ SD & Min-max & $\overline{\mathbf{X}} \pm \mathrm{SD}$ & Min-max & $\overline{\mathbf{X}} \pm$ SD & Min-max & $\bar{X} \pm$ SD & Min-max \\
\hline $\begin{array}{l}\text { Calendar age } \\
\text { [year] }\end{array}$ & $19.6 \pm 0.9$ & $18.5-24.0$ & $21.5 \pm 0.8$ & $20.0-25.0$ & $22.4 \pm 0.6$ & $21.5-23.0$ & $23.3 \pm 0.7$ & $22.5-26.0$ \\
\hline B-v $[\mathrm{cm}]$ & $180.4 \pm 5.7$ & 161.0-193.0 & $178.8 \pm 6.3$ & 165.1-197.0 & $181.9 \pm 5.5$ & $172.0-188.4$ & $180.9 \pm 6.0$ & $165.6-192.3$ \\
\hline $1 / 2(B-v)[c m]$ & $90.2 \pm 2.9$ & $80.5-96.5$ & $89.4 \pm 3.2$ & $82.6-98.5$ & $90.9 \pm 2.7$ & $86.0-94.2$ & $90.1 \pm 3.0$ & $82.8-96.2$ \\
\hline WC $[\mathrm{cm}]$ & $85.7 \pm 8.4$ & $68.0-121.0$ & $86.8 \pm 7.3$ & $74.0-113.0$ & - & - & - & - \\
\hline Body weight [kg] & $77.0 \pm 11.6$ & $52.7-120.0$ & $77.7 \pm 11.2$ & $55.2-118.7$ & $85.2 \pm 12.2$ & $68.7-115.1$ & $84.2 \pm 0.5$ & $64.6-103.1$ \\
\hline Fat [\%] & - & - & $24.9 \pm 4.4$ & $15.1-36.1$ & $27.3 \pm 3.9$ & $20.2-37.3$ & $27.4 \pm 3.5^{\star}$ & $19.4-33.4$ \\
\hline Water [\%] & - & - & $54.8 \pm 3.2$ & $46.6-61.9$ & $53.0 \pm 2.9$ & $45.7-58.2$ & $52.9 \pm 2.7 *$ & $48.6-58.8$ \\
\hline Muscle [\%] & - & - & $44.1 \pm 2.6$ & $34.6-50.7$ & $42.3 \pm 2.2$ & $37.3-45.7$ & $42.5 \pm 2.1^{* *}$ & $39.4-46.4$ \\
\hline BMI & $23.6 \pm 3.2$ & $15.8-34.7$ & $24.3 \pm 3.1$ & $18.8-35.3$ & $25.3 \pm 2.9 * *$ & $21.1-32.4$ & $25.7 \pm 2.8^{* \star}$ & $20.6-31.2$ \\
\hline WHR & $0.8 \pm 0.1$ & $0.7-1.1$ & $0.9 \pm 0.03$ & $0.7-1.0$ & - & - & - & - \\
\hline Rohrer's Index & $1.3 \pm 0.2$ & $0.9-1.9$ & $1.4 \pm 0.2$ & $1.1-1.9$ & $1.4 \pm 0.2$ & $1.1-1.7$ & $1.4 \pm 0.2^{*}$ & $1.1-1.8$ \\
\hline WHtR & $0.5 \pm 0.1$ & $0.4-0.6$ & $0.5 \pm 0.04$ & $0.4-0.6$ & - & - & - & - \\
\hline
\end{tabular}

${ }^{*} \mathrm{p}<0.01 ;{ }^{*} \mathrm{p}<0.001$; B-v - body height; WC - waist circumference; BMI - body mass index; WHR - waist-to-hip ratio; WHtR - waist-to-height ratio

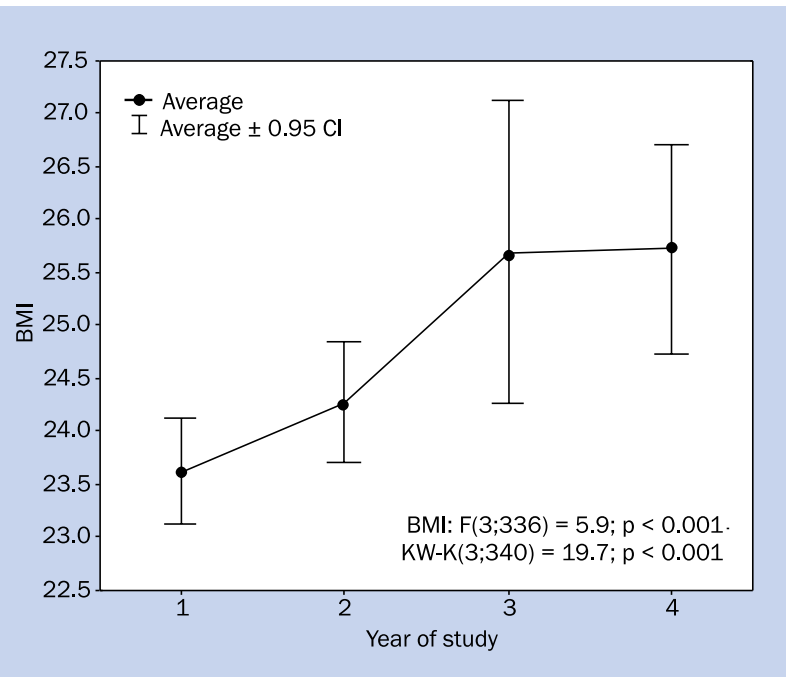

Figure 1. Average body mass index (BMI) to year of study (Kruskal-Wallis test, one-way ANOVA by ranks); $\mathrm{Cl}$ - confidence interval

Among the examined students, WC was higher than half the B-v in: $24.0 \%$ of first-year students and $32.2 \%$ second-year students. In the other groups, WC > 1/2 (B-v) was found in isolated cases (Tables 1, 2).

Data on body fat percentage were collected for students in years two, three and four. In the above-mentioned groups, the average body fat percentage amounted to respectively: $\bar{X}=24.9 \pm 4.4 \% ; \bar{X}=27.3 \pm 3.9 \% ; \bar{X}=27.4 \pm 3.5 \%$. The range of body fat percentage scores was very broad in the studied group. The Kruskal-Wallis ANOVA test revealed a statistical significance for $\mathrm{H}=12.8, \mathrm{p}=0.002$ (Fig. 3). The post-hoc analysis showed that the average body fat percentage in the fourth-year participants was significantly different $(p=0.004)$ from the average percentages of body fat in the second- and third-year students (Table 1).

\section{DISCUSSION}

Based on the general analysis of the somatic indices calculated for the studied population, judging by the arithmetic averages, the group can be characterised as mildly overweight with excess adiposity. Looking at the individual students, however, a large number exhibited a dangerous tendency to gain weight. According to BMI scores, more than half of the third- and fourth-year students had scores $\geq 25$ which corresponds to overweight. It is highly alarming that in the two youngest groups, individual WC measurements were higher than half the body height in $24.0 \%$ of the first-year participants and in $32.2 \%$ of the second-year students. The BMI scores obtained for the third and fourth year of study indicated a rapid increase of body weight in consecutive years of study. This finding is also confirmed by the Rohrer's Index findings. More than half of the students from the third and fourth year (respectively: $66.7 \%$ and $61.8 \%$ ) were characterised as having a stout figure. Moreover, $47.3 \%$ of the first-year students and $48.8 \%$ of the second-year students could also be categorised as stout. According to the WHtR, $4.2 \%$ of the first-year students and $8.3 \%$ of the second-year students were overweight to the point of having an increased risk of type 2 
Table 2. Somatic index categories - percentages and absolute numbers

\begin{tabular}{|c|c|c|c|c|}
\hline \multirow[t]{2}{*}{ Description } & \multicolumn{4}{|c|}{ Year of study - \% (n) } \\
\hline & First $(n=167)$ & Second $(n=121)$ & Third $(n=18)$ & Fourth $(n=34)$ \\
\hline \multicolumn{5}{|l|}{ Body mass index: } \\
\hline Underweight < 18.49 & $3.6(6)$ & - & - & - \\
\hline Normal 18.50-24.99 & $68.3(114)$ & $65.3(79)$ & $44.4(8)$ & $50.0(17)$ \\
\hline Overweight > 25.00 & $28.2(47)$ & $34.7(42)$ & $55.6(10)$ & $50.0(17)$ \\
\hline \multicolumn{5}{|l|}{ WC: } \\
\hline Android type $<1.0$ & $86.8(145)$ & $100(121)$ & - & - \\
\hline Gynoid type $\geq 1.0$ & $1.2(2)$ & - & - & - \\
\hline NA & $12.0(20)$ & - & $100.0(18)$ & $100.0(34)$ \\
\hline \multicolumn{5}{|l|}{ (B-v)-WC: } \\
\hline$[1 / 2(B-v)-W C]>1 / 2(B-v)$ & $24.0(40)$ & $32.2(39)$ & - & - \\
\hline$[1 / 2(B-v)-W C] \leq 1 / 2(B-v)$ & $64.1(107)$ & $67.8(82)$ & - & - \\
\hline NA & $12.0(20)$ & - & $100.0(18)$ & $100.0(34)$ \\
\hline \multicolumn{5}{|l|}{ Rohrer's Index: } \\
\hline Slender body build & $52.7(88)$ & $51.2(62)$ & $33.3(6)$ & $38.2(13)$ \\
\hline Stout body build & $47.3(79)$ & $48.8(59)$ & $66.7(12)$ & $61.8(21)$ \\
\hline \multicolumn{5}{|l|}{ WHtR: } \\
\hline Normal adiposity $<0.5$ & $67.7(113)$ & $71.1(86)$ & - & - \\
\hline Excess adiposity $>0.5$ & $20.36(34)$ & $28.9(35)$ & - & - \\
\hline NA & $12.0(20)$ & - & $100.0(18)$ & $100.0(34)$ \\
\hline \multicolumn{5}{|l|}{ WHtR: } \\
\hline$<0.56$ & $83.8(140)$ & $91.7(111)$ & - & - \\
\hline$\geq 0.56$ susceptibility to diabetes & $4.2(7)$ & $8.3(10)$ & - & - \\
\hline NA & 12.020 & - & $100.0(18)$ & $100.0(34)$ \\
\hline \multicolumn{5}{|l|}{ WHtR: } \\
\hline$<0.59$ & $86.2(144)$ & $98.4(119)$ & - & - \\
\hline$\geq 0.59$ susceptibility to hypertension & $1.8(3)$ & $1.7(2)$ & - & - \\
\hline NA & $12.0(20)$ & - & $100.0(18)$ & $100.0(34)$ \\
\hline
\end{tabular}

B-v - body height; WC - waist circumference; WHtR - waist-to-height ratio; NA - not available

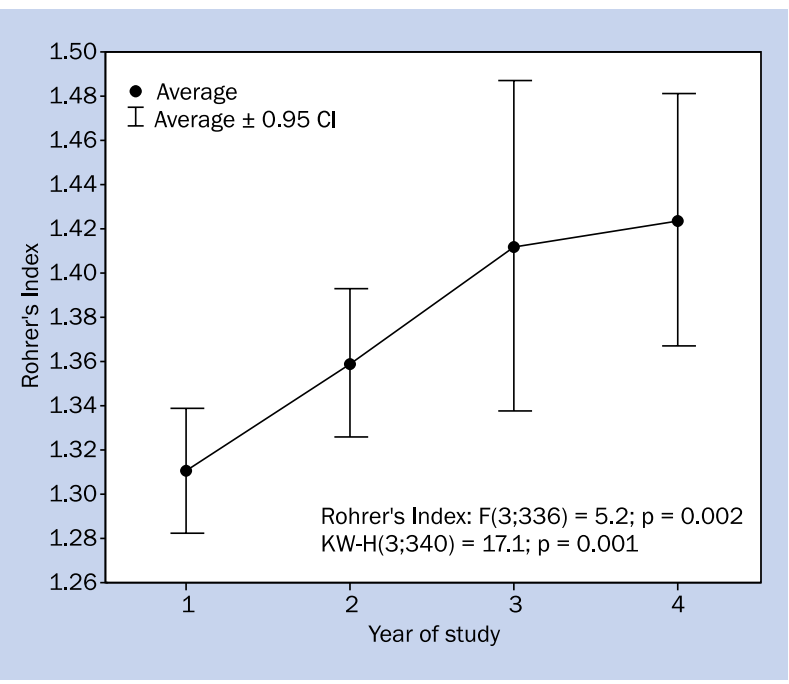

Figure 2. Average Rohrer's Index to year of study (Kruskal-Wallis test, one-way ANOVA by ranks); $\mathrm{Cl}$ - confidence interval

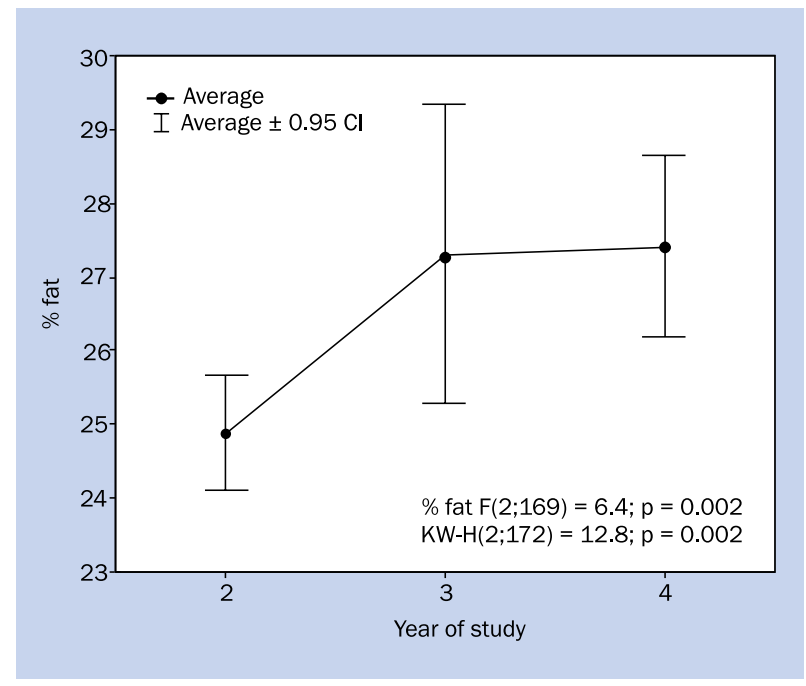

Figure 3. Average fat [\%] to year of study (Kruskal-Wallis test, one-way ANOVA by ranks); $\mathrm{Cl}$ - confidence interval 
diabetes (WHtR $\geq 0.56$ ). For these young men, starting a job at sea, which involves relative isolation, may be imprudent or plain dangerous. The same goes for the three first-year students and two second-year students in whom WHtR $\geq 0.59$ was found, which apart from diabetes, also carries the risk of developing arterial hypertension [21, 22].

It should be highlighted that according to Rohrer's Index, the percentage of stout individuals increased with each year of study. The BIA findings at the same time reveal that among the studied group each subsequent year of study brought an increase of the body fat percentage in the total body weight, and a decrease of the lean mass (fat-free body mass). This may confirm the observation that changes in the body build of future seamen tend to involve increasing adiposity and weight gain. It is worrying that only a small percentage of students in education put in the effort to stay slim and physically fit.

Obesity and overweight are recognised as a $21^{\text {st }}$ century epidemic, which is reaching pandemic proportions. In a number of European Union states, there are concerns over the growth dynamics of the overweight and obese population. According to Eurostat data [23], the percentage of overweight and obese men in the 18-24 age group in 2009 was estimated at more than $30 \%$. This figure doubles once we move to the 25-44 age range in men. Bridger et al. [24] suggest that at the age of 45 , the average weight of men and women is $\sim 20 \%$ higher than it was 20 years earlier. Such a high increment points to a dramatic increase in the number of people who are having difficulties maintaining normal body weight during their most active working years. The present findings for a very specific group, i.e. candidates for careers at sea, give cause for concern. In light of the examinations performed, choosing the right somatic index to predict overweight seems to pose a challenge. The international consensus on the utility of the BMI, which has been used for decades to determine normal body weight, is gradually declining. The analysis of the collected material shows that students whose BMI was in the normal range could still find themselves in the overweight category according to other indices.

More and more often the recruitment procedures for particular jobs, not just those at sea, involve testing a series of parameters (the so-called Work Ability Index - WAI) such as medical indications, intellectual ability, physical condition, etc. The WAl is used not only to assess the current ability to work, but also to prevent occupational health risks (such as that of disability). Studies have shown that advanced age and high BMI scores have a significant impact on the WAI. Older personnel with high BMI reported lower work ability. Bridger et al. [24] demonstrated that work ability declines at about 47 years of age in people with $\mathrm{BMI} \geq 30$. For those with $\mathrm{BMI} \leq 25$ work ability drops at the age of $>56$, i.e. nine years later. It would be difficult to indicate a strict upper-limit $\mathrm{BMI} /$ calendar age as a recruitment criterion for working at sea, because it could be perceived as a discriminatory practice. However, the presented findings reveal a considerable prevalence of overweight among the prospective seamen, with a clear upward trend for the future. It is striking that even some first-year students were found to be overweight. The number of obese students according to BMI is lower in the first and second year of study, compared to years three and four In terms of Rohrer's Index the number of stout individuals is also similar. This suggests that the levels of adiposity are comparable, but with different distribution of body fat.

Candidates to work at sea should enjoy particularly good health and physical fitness. A pronounced increase in body weight and adiposity in subsequent years of study means that maritime university students are subject to the same weight gain trends as their peers at other universities. Verification of fitness for a career at sea stops at university recruitment. In later years, physical fitness and good health are not priority issues any more, as evidenced by absenteeism in the course of this study. The curriculum does not include regular classes aimed at promoting health, good diet, the role of sports in everyday life, health consequences of risky behaviours (alcohol, nicotine, drugs etc.).

\section{CONCLUSIONS}

1. There is a secular trend which is observed and reported more and more in developed countries: societies age and there are increasing numbers of obese and overweight people.

2. The growing global risk of excess weight also affects jobs which pose particularly strict requirements with regard to good health and physical condition.

3. Recruitment for uniformed professions will most probably tend to be less restrictive (competitive), because it is getting harder and harder to find candidates who are trim enough to boast normal BMI (in the healthy range) at the end of their education.

4. Health promotion including weight control should be a priority among future seamen (and women).

5. Responsibility for one's own health and body shape is not sufficiently promoted throughout the course of studies preparing for work at sea.

\section{REFERENCES}

1. Global Health Observatory (GHO) data [Internet]. Mean Body Mass Index (BMI) [cited 2015 April 23]. Available from: http://www.who. int/gho/ncd/risk_factors/bmi_text/en/.

2. Nutrition [Internet]. Controlling the global obesity epidemic [cited 2015 April 23]. Available from: http://www.who.int/nmh/countries/ en/\#T.

3. Mansour AA, Al-Jazairi MI. Cut-off values for anthropometric variables that confer increased risk of type 2 diabetes mellitus and hyperten- 
sion in Iraq. Archiv Med Res 2007; 38: 253-258. doi: 10.1016/ j.arcmed.2006.09.014.

4. Dietz W. Critical periods in childhood for the development of obesity. Am J Clin Nutr 1994; 59: 955-959.

5. Ejike C, ljeh I. Obesity in young-adult Nigerians: variations in prevalence determined by anthropometry and bioelectrical impedance analysis, and the development of $\%$ body fat prediction equations. Int Arch Med 2012; 5: 22. doi: 10.1186/1755-7682-5-22.

6. Physical status: the Use and Interpretation of Anthropometry. Report of a WHO expert committee. WHO Tech Rep Ser 854. Geneva 1995; p.452.

7. Hemmingsson $\mathrm{E}$, Ekelund $\mathrm{U}$. Is the association between physical activity and body mass index obesity dependent? Int J Obes (Lond) 2007; 31: 663-668. doi: 10.1038/sj.ijo.0803458.

8. Sung RY, So HK, Choi KC, Nelson EA, Li AM, Yin JA, Fok TF. Waist circumference and waist-to-height ratio of Hong Kong Chinese children. BMC Public Health 2008; 8: 324. doi: 10.1186/1471 2458-8-324.

9. Haun DR, Pitanga FJ, Lessa I. Waist-height ratio compared to other anthropometric indicators of obesity as predictors of high coronary risk. Rev Assoc Med Bras 2009; 55: 705-711.

10. Knowles KM, Paiva LL, Sanchez SE et al. Waist circumference, body mass index, and other measures of adiposity in predicting cardiovascular disease risk factors among Peruvian adults. Int J Hypertens 2011; 2011: 931402. doi: 10.4061/2011/931402.

11. Bener A, Yousafzai MT, Darwish S, Al-Hamaq AO, Nasralla EA, Abdul-Ghani M. Obesity index that better predict metabolic syndrome: body mass index, waist circumference, waist hip ratio, or waist height ratio. J Obes 2013; 2013: 269038. doi: 10.1155/2013/269038.

12. Nawarycz T, Haas GM, Krzyzaniak A, Schwandt P, Ostrowska-Nawarycz L. Waist circumference and waist-to-height ratio distributions in Polish and German schoolchildren: comparative analysis. Int J Prev Med 2013; 4: 786-796.

13. Ashwell M, Hsieh SD. Six reasons why the waist-to-height ratio is a rapid and effective global indicator for health risks of obesity and how its use could simplify the international public health message on obesity. Int J Food Sci Nutr 2005; 56: 303-307. doi: 10.1080/09637480500195066.
14. Martin R, Saller K. Lehrbuch der Anthropologie in Systematischer Darstellung. Gustav Fischer Verlag, Stuttgart 1958.

15. Drozdowski Z. Antropometria w wychowaniu fizycznym. AWF, Poznań 1998 (in Polish).

16. Ashwell M, Gunn P, Gibson S. Waist-to-height ratio is a better screening tool than waist circumference and $\mathrm{BMI}$ for adult cardiometabolic risk factors: systematic review and meta-analysis. Obes Rev 2012; 13: 275-286. doi: 10.1111/j. 1467-789X.2011.00952.x.

17. Lee CM, Huxley RR, Wildman RP, Woodward M. Indices of abdominal obesity are better discriminators of cardiovascular risk factors than BMI: a meta-analysis. J Clin Epidemiol 2008; 61: 646-653. doi: 10.1016/j.jclinepi.2007.08.012.

18. Dalton M, Cameron AJ, Zimmet PZ et al. Waist circumference, waist-hip ratio and body mass index and their correlation with cardiovascular disease risk factors in Australian adults. J Intern Med 2003; 254: 555-563.

19. World Health Organization. Obesity - Preventing and Managing the Global Epidemic: Report of a WHO Consultation on Obesity. World Health Organization, Geneva 1998; p. 276.

20. Gallagher D, Heymsfield SB, Heo M, Jebb SA, Murgatroyd PR, Sakamoto $Y$. Healthy percentage body fat ranges: an approach for developing guidelines based on body mass index. Am J Clin Nutr 2000; 72: 694-701.

21. Grober-Gratz D, Widhalm K, de Zwaan M et al. Body mass index or waist circumference: which is the better predictor for hypertension and dyslipidemia in overweight/obese children and adolescents? Association of cardiovascular risk related to body mass index or waist circumference. Horm Res Paediatr 2013; 80: 170-178, doi: $10.1159 / 000354224$.

22. Grundy SM, Neeland IJ, Turer AT, Vega GL. Waist circumference as measure of abdominal fat compartments. J Obes 2013; 2013: 454285. doi: $10.1155 / 2013 / 454285$.

23. Eurostat. Your key to European statistics [Internet]. Available from: http://ec.europa.eu/eurostat [cited 2015 Apr 22].

24. Bridger RS, Bennett Al. Age and BMI interact to determine work ability in seafarers. Occup Med (Lond) 2011; 61: 157-162. doi: 10.1093/occmed/kqr003. 